\title{
DESKRIPSI PENGETAHUAN REMAJA PUTRI TENTANG DISMENORE DI KELURAHAN BENJALA KECAMATAN BONTOBAHARI KABUPATEN BULUKUMBA
}

\author{
Haerani*, Sri Ningsih, Ulfa Dillah, Nurul Hidayah Bohari, Nita Ariani Nur, A. Maya Rupa A, \\ Mudyawati Kamaruddin \\ Program Studi Kebidanan, Akademi Kebidanan Tahirah Al Baeti, Bulukumba, Sulawesi Selatan \\ *Corresponding author : Telp :+ 6285242473342, email : haeranirani987@ gmail.com
}

\begin{abstract}
ABSTRAK
Dismenore didefinisikan sebagai nyeri pada saat haid. Istilah dismenore (dysmenorrhea) berasal dari kata dalam bahasa yunani kuno (Greek) kata tersebut berasal dari dys yang berarti sulit, nyeri, abnormal; meno yang berarti bulan; dan rrhea yang berarti aliran atau arus. Secara singkat dismenore dapat di definisikan sebagai aliran menstruasi yang sulit atau menstruasi yang mengalami nyeri. untuk mengetahui gambaran pengetahuan remaja tentang Dismenore di Kelurahan Benjala Kecamatan Bontobahari Kabupaten Bulukumba Jenis penelitian ini menggunakan penelitian deskriptif untuk mengetahui gambaran pengetahuan remaja tentang dismenore di Kelurahan Benjala Kecamatan Bontobahari Kabupaten Bulukumba. Populasi dalam penelitian ini adalah remaja usia 15-19 tahun yang berjuamlah 125 orang yang berdomisili di Kelurahan BenjalaKecamatan Bontobahari Kabupaten Bulukumba. Jumlah Sampel dalam penelitian ini adalah sebanyak 38 orang. Tehnik pengambilan sampel dalam penelitian ini adalah Purposive sampling. Pengumpulan data menggunakan lembar kuesioner. Gambaran Pengetahuan Remaja Tentang Dismenore Di Kelurahan Benjala Kecamatan Bontobahari Kabupaten Bulukumba sebanyak 38 responde terdapat pengetahuan baik sebanyak 0 responden (0\%), pengetahuan cukup sebanyak 8 responden $(21,1 \%)$, dan yang mempunyai pengetahuan kurang sebanyak 30 responden (78,9\%). Gambaran Pengetahuan Remaja Tentang Dismenore Di Kelurahan Benjala Kecamatan Bontobahari Kabupaten Bulukumba sebagian besar memiliki tingkat pengetahuan cukup yaitu sebanyak 30 responden $(78,9 \%)$. diharapkan bagi peneliti selanjutnya untuk dapat mengembangkan variable penelitian dan sampel penelitian.
\end{abstract}

Kata Kunci: Pengetahuan, Remaja, Menstruasi, Dismenore

\begin{abstract}
Dysmenorrhea is defined as painful period or menstrual cramps. The term of dysmenorrhea derived from the Greek words, "dys" means difficult, painful, abnormal, while "meno" means month, and "rrhea" means flow. This dysmenorrhea can be defined as the painful menstrual. This research was conducted in order to figure out the knowledge of teenagers due to dysmenorrhea at Benjala Urban Village the Bontobahari Sub-district of Bulukumba Regency. This research used descriptive quantitative design with total 125 teenagers in the aged 15 until 19 years old who live in Benjala Urban Village the Bontobahari Sub-district of Bulukumba Regency. This research used 38 samples by purposive sampling, and the instrument was collected by questionnaire. The result of this research showed that among 38 respondents, there were 8 respondents $(21.1 \%)$ categorized have fairly knowledge, 30 respondents (78.9\%) in having poor knowledge, and none of the respondent have good knowledge. Conclusion of this research that the knowledge of teenagers about dysmenorrhea mostly in fairly category.
\end{abstract}

Keywords: Dysmenorrhea, Menstrual, Knowledge, Teenagers.

\section{PENDAHULUAN}

Dismenore merupakan salah satu yang sering terdengar, penyakit ini sering dianggap remeh dan dianggap tidak perlu ditangani secara serius. Padahal, penyakit ini sungguh tidak sesederhana yang dibayangkan oleh banyak orang. Ada banyak aspek yang melatarbelakangi terjadinya nyeri haid dan semuanya harus ditangani secara bijaksana agar tidak mengganggu kesehatan secara keseluruhan. 
Dismenore didefinisikan sebagai nyeri pada saat haid. Istilah dismenore (dysmenorrhea) berasal dari kata dalam bahasa yunani kuno (Greek) kata tersebut berasal dari dys yang berarti sulit, nyeri, abnormal; meno yang berarti bulan; dan rrhea yang berarti aliran atau arus. Secara singkat dismenore dapat di definisikan sebagai aliran menstruasi yang sulit atau menstruasi yang mengalami nyeri (Anurogo dan Wulandari, 2011:33).

Menurut Mulastin (2013: 98-100), angka kejadian dismenore di dunia sangat besar. Rata rata lebih dari $50 \%$ perempuan di setiap negara mengalami dismenore. Sementara menurut Anurogo dan wulandari (2011:36-39), prevalensi dismenore didunia sangatlah besar, rata-rata lebih dari $50 \%$ wanita disetiap negara mengalami nyeri haid. Di negara-negara barat prevalensi dismenore sangatlah besar dibandingkan dengan di negaranegara Asia. Di Amerika Serikat, prevalensi kejadiannya diperkirakan hampir 45-90\%. Dalam studi epidemiologi pada pupulasi remaja berusia 12-17 tahun, Klein dan Litt melaporkan prevalensi dismenore $59,7 \%$. Dari mereka yang mengeluh nyeri $12 \%$ berat, $37 \%$ sedang dan $49 \%$ ringan. Studi ini juga melaporkan bahwa dismenore menyebabkan $14 \%$ remaja putri sering tidak masuk sekolah.

Diperkirakan prevalensi dismenore di Indonesia sebesar 55\% dari jumlah perempuan usia produktif yang ada. Penelitian yang dilakukan oleh Handayani (2013: 76), mendapati bahwa prevalensi dismenorea pada remaja di Kota Surakarta sebesar $87 \%$. Kemudian penelitian yang dilakukan oleh Lestari (2010:111), di Manado, didapati dari 200 responden, 199 responden diantaranya (98.5\%) pernah mengalami dismenore. Selanjutnya penelitian yang dilakukan oleh Sutanto (2008) di Makassar, 93,8\% remaja putri mengalami dismenore. Sedangkan penelitian yang dilakukan oleh Utami (2013:114), pada remaja putri di sebuah SMA di kabupaten Bone menunjukkan hasil $87,1 \%$ remaja putri mengalami dismenore. Dan penelitian yang serupa yang pernah dilakukan oleh Musakkkar (2012:33-34), pada siswi kelas 1 di SMA Karya Sahari Bulukumba mendapatkan hasil 43,53\% siswi berpengetahuan baik tentang pengertian dismenore, $48,23 \%$ berpengetahuan baik tentang penyebab dismenore, $64,70 \%$ siswi berpengetahuan baik tentang pencegahan dismenore, dan 35,29\% berpengetahuan baik tentang penanganan dismenore.

Peneliti memilih Kelurahan Benjala sebagai lokasi penelitian karena di Kelurahan ini terdapat banyak remaja dengan rentang usia diatas 13 tahun dimana ini sudah termasuk dalam kategori remaja yang telah mengalami menarche. Selain itu, studi pendahuluan yang pernah dilakukan peneliti dengan mewawancarai 15 orang remaja yang berdomisili di Kelurahan Benjala secara acak ditemukan hasil 7 orang hanya mengetahui hanya sebatas tentang rasa nyeri saat menstruasi merupakan hal yang biasa, 5 orang remaja mengaku tidak pernah mendengar dan tidak paham sama sekali tentang rasa nyeri saat menstruasi, namun ada 3 diantaranya pernah mengalami rasa nyeri saat menstruasi sampai tidak dapat beraktivitas. Hal ini menjadi salah satu bukti bahwa masih rendahnya pengetahuan remaja tentang dismenore.

\section{METODOLOGI Jenis penelitian}

Jenis penelitian ini menggunakan penelitian deskriptifuntuk mengetahui gambaran pengetahuan remaja putri tentang dismenore di Kelurahan Benjala Kecamatan Bontobahari Kabupaten Bulukumba

\section{Tempat dan waktu Penelitian}

\section{Lokasi penelitian}

Lokasi Penelitian ini telah di laksanakan di Kelurahan Benjala Kecamatan Bontobahari Kabupaten Bulukumba

2. Waktu penelitian

Penelitian ini telahdilaksanakan pada 1 Juni 9 Juli 2019.

\section{Populasi, Sampel, dan Tehnik Pengambilan Sampel}

a. Populasi

Populasi dalam penelitian ini adalah remaja berusia 15-19 tahun yang berjuamlah 125 orang remaja berdasarkan pendataan terakhir tahun 2017 yang berdomisili di Kelurahan Benjala.

b. Sampel

Sampel dalam penelitian ini adalah 38 orang remaja di Kelurahan Benjala Kabupaten Bulukumba Kabupaten Bulukumba.

c. Tehnik Pengambilan Sampel

Pengambilan sampel dalam penelitian ini adalah Purposive sampling. Karena pop ulasi yang digunakan relatif besar. Purposive sampling adalah pengambilan sampel yang berdasarkan atas suatu 
pertimbangan tertentu seperti sifat-sifat populasi ataupun ciri-ciri yang sudah diketahui sebelumnya (Notoadmodjo: 2012: 21).

\section{Ruang Lingkup Penelitian}

Ruang lingkup penenlitian ini mencakup tentang gambaran pengetahuan remaja tentang dismenore di Kelurahan Benjala Kecamatan Bontobahari Kabupaten Bulukumba.

\section{Tekhnik Pengumpulan Data}

Pengumpulan data dilakukan dengan cara meminta izin secara administrasi kepada Kepala Kelurahan Benjala untuk melakukan penelitian. Kemudian peneliti membagikn lembar kuesioner dilapangan pada remaja Kelurahan Benjala Kecamatan Bontobahari Kabupaten Bulukumba dengan terlebih dahulu menjelaskan maksud dan tujuan pengumpulan data dengan cara angket karena dalam penelitian ini, peneliti tidak hanya memikirkan kepentingan sendiri, tetapi harus mempertimbangkan faktor-faktor yang ada pada diri responden, serta menjelaskan tata cara pengisian lembar kuesioner.

Peneliti membagikan lembar tes di MTS pada siswi MTS Guppi Batuara Kabupaten Bulukumba dan menjelaskan maksud dan tujuan pengumpulan data dalam penelitian ini, serta menjelaskan tata cara pengisian lembar tes.

\section{Analisa Data}

Dalam analisa data dideskripsikan angka atau nilai jumlah variabel dengan ukuran presentase dengan menggunakan rumus frekuensi presentase (Sugiyono, 2012: 129).

$$
\begin{aligned}
& \qquad \mathrm{P}=\frac{F}{N} \times 100 \% \\
& \text { Keterangan: } \\
& \mathrm{F} \text { : Jumlah frekuensi } \\
& \mathrm{N} \text { : Jumlah responden yang diseleksi } \\
& \mathrm{P} \text { :Angka presentas }
\end{aligned}
$$

\section{HASIL DAN PEMBAHASAN \\ Hasil}

Berikut ini hasil penelitian mengenai gambaran pengetahuan remaja putri tentang dismenore di Kelurahan Benjala Kecamatan Bontobahari Kabupaten Bulukumba yang dilaksanakan pada tanggal 1 Juni sampai dengan 9 Juli 2019
1. Karakteristik Subjek Penelitian

a. Berdasarkan hasil penelitian yang telah dilakukan maka didapatkan sebanyak 38 responden yang terdiri dari remaja usia 15-19 tahun.

Tabel 4.1 Distribusi Frekuensi Pengetahuan Remaja Putri Tentang Dismenore Berdasarkan Umur Di Kelurahan Benjala Kecamatan Bontobahari Kabupaten Bulukumba

\begin{tabular}{c|c|c}
\hline Umur & N & $\begin{array}{c}\text { Presentase } \\
(\boldsymbol{\%})\end{array}$ \\
\hline $15-16$ & 14 & 36,8 \\
$17-18$ & 18 & 47,4 \\
19 & 6 & 15,8 \\
\hline Total & $\mathbf{3 8}$ & $\mathbf{1 0 0}$ \\
\hline
\end{tabular}

Sumber: Data primer (2019)

Berdasarkan tabel 4.1 diketahui bahwa dari 38 responden terdapat umur 15-16 tahun sebanyak 14remaja (36,8\%), umur 17-18 tahun sebanyak 18remaja $(47,4 \%)$, umur 19 tahun sebanyak 6remaja $(15,8 \%)$.

b. Berdasarkan hasil penelitian yang telah dilakukan maka didapatkan sebanyak 38 responden yang terdiri dari remaja usia menarche 13-17 tahun.

Tabel 4.2 Distribusi Frekuensi Pengetahuan Remaja Putri Tentang Dismenore Berdasarkan Umur Menarche Di Kelurahan Benjala Kecamatan Bontobahari Kabupaten Bulukumba

\begin{tabular}{c|c|c}
\hline Umur & $\mathbf{N}$ & $\begin{array}{c}\text { Presentase } \\
(\mathbf{\%})\end{array}$ \\
\hline $13-14$ & 36 & 94,7 \\
$15-16$ & 1 & 2,6 \\
17 & 1 & 2,6 \\
\hline Total & $\mathbf{3 8}$ & $\mathbf{1 0 0}$ \\
\hline
\end{tabular}

Sumber: Data primer (2019)

Berdasarkan tabel 4.2 diketahui bahwa dari 38 responden terdapat umur menarche 13-14 tahun sebanyak 36remaja $(94,7 \%)$, umur 15-16 tahun sebanyak 1 remaja $(2,6 \%)$, umur 17 tahun sebanyak 1remaja $(2,6 \%)$.

\section{Analisa hasil penelitian}

a. Gambaran Pengetahuan Remaja Putri Tentang Gangguan Menstruasi 
Tabel 4.3 Distribusi Pengetahuan Remaja Putri Tentang Gangguan Menstruasi Di Kelurahan Benjala Kecamatan Bontobahari Kabupaten Bulukumba

\begin{tabular}{c|c|c}
\hline $\begin{array}{c}\text { Gangguan } \\
\text { Menstruasi }\end{array}$ & N & $\begin{array}{c}\text { Presentase } \\
(\%)\end{array}$ \\
\hline Baik & 4 & 10,5 \\
Cukup & 25 & 65,8 \\
Kurang & 9 & 23,7 \\
\hline Total & $\mathbf{3 8}$ & $\mathbf{1 0 0}$ \\
\hline
\end{tabular}

Sumber : Data primer (2019)

Berdasarkan tabel 4.3diketahuai bahwa dari 38 responden terdapat pengetahuan baik sebanyak 4 responden $(10,5 \%)$, yang pengetahuan cukup sebanyak 25 responden $(65,8 \%)$, dan yang mempunyai pengetahuan kurang sebanyak 9 responden $(23,7 \%)$ tentang gangguan menstruasi.

\section{b.Gambaran Pengetahuan Remaja Putri \\ Kelurahan Benjala Tentang Pengertian \\ Dismenore}

Tabel 4.4 Distribusi Pengetahuan Remaja Putri Tentang Pengertian Dismenore Di Kelurahan Benjala Kecamatan Bontobahari Kabupaten Bulukumba

\begin{tabular}{c|c|c}
\hline $\begin{array}{c}\text { Pengertian } \\
\text { Dismenore }\end{array}$ & $\mathbf{N}$ & $\begin{array}{c}\text { Presentasi } \\
(\mathbf{\%})\end{array}$ \\
\hline Baik & 9 & 23,7 \\
Cukup & 19 & 50,0 \\
Kurang & 10 & 26,3 \\
\hline Total & $\mathbf{3 8}$ & $\mathbf{1 0 0}$ \\
\hline
\end{tabular}

Sumber : Data primer (2019)

Berdasarkan tabel 4.4diketahui bahwa dari 38 responden terdapat yang pengetahuan baik sebanyak 9 responden $(23,7 \%)$, pengetahuan cukup sebanyak 19 responden $(50,0 \%)$, dan yang memiliki pengetahuan kurang sebanyak 4.70 responden $(26,3 \%)$ tentang pengertian dismenore.

c. Gambaran Pengetahuan Remaja Putri

Kelurahan Benjala Tentang Faktor Yang Mempengaruhi Dismenore

Tabel 4.5 Distribusi Pengetahuan Remaja Putri Tentang Faktor Penyebab Yang Mempengaruhi Dismenore Di Kelurahan Benjala Kecamatan Bontobahari Kabupaten Bulukumba

\begin{tabular}{|c|c|c|}
\hline $\begin{array}{l}\text { Faktor Penyebab } \\
\text { Yang } \\
\text { Mempengaruhi } \\
\text { Dismenore }\end{array}$ & $\mathbf{N}$ & $\begin{array}{c}\text { Presentase } \\
(\%)\end{array}$ \\
\hline Baik & 14 & 36,8 \\
\hline Cukup & 21 & 55,3 \\
\hline Kurang & 3 & 7.9 \\
\hline Total & 38 & 100 \\
\hline
\end{tabular}

Berdasarkan tabel 4.5diketahuai bahwa dari 38 respondenterdapat yang pengetahuan baik sebanyak 14 responden $(36,8 \%)$, pengetahuan cukup sebanyak 21 responden $(55,3 \%)$, dan yang mempunyai pengetahuan kurang sebanyak 3 responden $(7,9 \%)$ tentang faktor penyebab yang mempengaruhi dismenore.

d.Gambaran Pengetahuan Remaja Putri Kelurahan Benjala Tentang Gejala Dismenore

Tabel 4.6 Distribusi Pengetahuan Remaja Putri Tentang Gejala Dismenore Di Kelurahan Benjala Kecamatan Bontobahari Kabupaten Bulukumba

\begin{tabular}{|c|c|c|}
\hline Gejala Dismenore & $\mathbf{N}$ & $\begin{array}{c}\text { Presentase } \\
(\%)\end{array}$ \\
\hline Baik & 14 & 36.8 \\
\hline Cukup & 14 & 36,8 \\
\hline Kurang & 10 & 26,3 \\
\hline Total & 38 & 100 \\
\hline
\end{tabular}

Berdasarkan tabel 4.6diketahui bahwa dari 38 responden terdapat yang memiliki pengetahuan baik sebanyak 14 responden $(36,8 \%)$, pengetahuan cukup sebanyak 14 responden $(36,8 \%)$, dan yang mempunyai pengetahuan kurang sebanyak 10 responden $(26,3 \%)$ tentang gejala dismenore.

e. Gambaran Pengetahuan Remaja Putri Kelurahan Benjala Tentang Pencegahan Dismenore

Tabel 4.7 Distribusi Pengetahuan Remaja Putri Tentang Pencegahan Dismenore Di Kelurahan Benjala Kecamatan Bontobahari Kabupaten Bulukumba

\begin{tabular}{c|c|c}
\hline Pencegahan Dismenore & N & $\begin{array}{c}\text { Presentase } \\
(\mathbf{\%})\end{array}$ \\
\hline Baik & 3 & 7,9 \\
Cukup & 20 & 52,6 \\
Kurang & 15 & 39,5 \\
\hline Total & $\mathbf{3 8}$ & $\mathbf{1 0 0}$ \\
\hline
\end{tabular}

Sumber : Data primer (2019) 
Berdasarkan tabel 4.7diketahui bahwa dari 38 responden terdapat yang memiliki pengetahuan baik sebanyak 3 responden $(7,9 \%)$, pengetahuan cukup sebanyak 20 responden $(52,6 \%)$, dan yang mempunyai pengetahuan kurang sebanyak 15 responden $(39,5 \%)$ tentang pencegahan dismenore.

f. Gambaran Pengetahuan Remaja Putri Kelurahan Benjala Tentang Penanganan Dismenore

Tabel 4.8 Distribusi Pengetahuan Remaja Putri Tentang Penanganan Dismenore Di Kelurahan Benjala Kecamatan Bontobahari Kabupaten Bulukumba

\begin{tabular}{c|c|c}
\hline $\begin{array}{c}\text { Penanganan } \\
\text { Dismenore }\end{array}$ & $\mathbf{N}$ & $\begin{array}{c}\text { Presentase } \\
(\boldsymbol{\%})\end{array}$ \\
\hline Baik & 8 & 21,1 \\
Cukup & 26 & 68,4 \\
Kurang & 4 & 10,5 \\
\hline Total & $\mathbf{3 8}$ & $\mathbf{1 0 0}$ \\
\hline
\end{tabular}

Sumber : Data primer (2019)

Berdasarkan tabel 4.8diketahui bahwa dari 38 responden terdapat yang memilikipengetahuan baik sebanyak 8 responden $(21,1 \%)$, pengetahuan cukup sebanyak 26 responden $(68,4 \%)$, dan yang mempunyai pengetahuan kurang sebanyak 4 responden $(10,5 \%)$ tentang penanganan dismenore.

g.Gambaran Pengetahuan Remaja Putri Kelurahan Benjala Tentang Tentang Dismenore Tabel 4.9 Distribusi Pengetahuan Remaja Putri Tentang Dismenore Di Kelurahan Benjala Kecamatan Bontobahari Kabupaten Bulukumba

\begin{tabular}{c|c|c}
\hline $\begin{array}{c}\text { Gambaran } \\
\text { Pengetahuan } \\
\text { Dismenore }\end{array}$ & $\mathbf{N}$ & $\begin{array}{c}\text { Presentase } \\
(\mathbf{\%})\end{array}$ \\
\hline Baik & 0 & 0 \\
Cukup & 8 & 21,1 \\
Kurang & 30 & 78,9 \\
\hline Total & $\mathbf{3 8}$ & $\mathbf{1 0 0}$ \\
\hline
\end{tabular}

Sumber : Data primer (2019)

Berdasarkan tabel 4.9diketahui bahwa dari 38 respondenterdapat yang memiliki pengetahuan baik sebanyak 0 responden $(0 \%)$, pengetahuan cukup sebanyak 8 responden $(21,1 \%)$, dan yang mempunyai pengetahuan kurang sebanyak 30 responden $(78,9 \%)$ tentang dismenore.

\section{Pembahasan}

\section{1) Gangguan menstruasi}

Gangguan yang sering terjadi antara lain siklus menstruasi yang tidak benar, gangguan volume menstruasi baik perdarahan yang lama atau abnormal, gangguan nyeri atau dismenore, atau sindroma pramenstruasi. Pada sebagian wanita, didapatkan siklus menstruasi yang panjang dan dapat berlangsung hingga 35 hari, namun durasi ini bervariasi tergantung individunya (Sasaki, 2014: 21).

Hasil penelitian mengemukakan bahwa pengetahuan remaja tentang gangguan menstruasi sebagian besar dalam kriteria cukup yaitu sebanyak 25 responden $(65,8 \%)$. Dari hasil penelitian tersebut maka ditemukan adanya kesesuai antara teori dengan hasil penelitian yang mengatakan bahwa pengetahuan yang cukup tidak hanya didukung oleh pengalaman yang ada tetapi juga dipengaruhi oleh lingkungan dan informasi yang dapat diperoleh. Dimana remaja di Kelurahan Benjala masih memiliki pengetahuan yang cukup tentang gangguan menstruasi, karena kurangnya pengalaman dan pengaruh pergaulan di lingkungan yang kurang memanfaatkan media massa untuk memperoleh informasi tentang kesehatan.

Hal ini sejalan dengan penelitian yang dilakukan oleh Wilandania (2015: 56), gambaran tingkat pengetahuan remaja putri tentang gangguan menstruasi pada siswi kelas XI di SMAN 13 Surabaya. Hasil penelitian menunjukkan dari 68 siswi sebagian besar memiliki tingkat pengetahuan cukup sebanyak 37 siswi $(54,4 \%)$, sedangkan hamper setengahnya memiliki pengetahuan baik sebanyak 27 siswi (39,7\%), sisanya sebagian kecil memiliki pengetahuan yang kurang sebanyak 4 siswi $(5,9 \%)$.

\section{1) Pengertian Dismenore}

Dysmenorrhea atau dismenore dalam bahasa Indonesia berarti nyeri pada saat menstruasi. Dismenore yakni nyeri menstruasi yang dikarakteristikan sebagai nyeri singkat sebelum atau selama menstruasi. Nyeri ini berlangsung selama satu sampai beberapa hari selama menstruasi (Sukarni dan Wahyu 2013: 37).

Hasil penelitian mengemukakan bahwa pengetahuan remaja tentang pengertian dismenore sebagian besar dalam kriteria cukup yaitu sebanyak 19 responden $(50,0 \%)$. Pengetahuan remaja di kelurahan Benjala yang yang cukup menunjukkan 
bahwa rata-rata dari mereka memiliki pengetahuan tentang pengertian dysmenorhoe walaupun hanya sebatas tahudan tidak sampai memahami. Hal ini sesuai dengan teori pengetahuan Notoadmodjo (2012: 15), yang menjelaskan beberapa tingkat pengetahuan diantaranya tahu dan memahami. Dimana tahu diartikan sebagai mengingat suatu materi yang telah dipelajari sebelumnya. Sementara memahami merupakan suatu kemampuan untuk menjelaskan secara benar suatu objekyang diketahui.

Hal ini sejalan dengan hasil penelitian yang diapatkan oleh peneliti sebelumnya oleh Defi Nafiroh dan Nuke Devi Indrawati, 2013: 157 - 166, Gambaran Pengetahuan Remaja Tentang Dismenore Pada Siswa Putri Di Mts Nu Mranggen Kabupaten Demak. Hasil penelitian yang diperoleh adalah mayoritas responden merupakan remaja pertengahan (umur 13 - 15 tahun) yaitu $84,8 \%$ dan mayoritas responden memiliki pengetahuan kurang tentang Dismenore sebesar 78,3\%. Kesimpulan mayoritas responden memiliki pengetahuan kurang tentang Dismenore yaitu sebesar 36 siswi $(78,3 \%)$.

2) Faktor penyebab yang mempengaruhi dismenore

Menurut Anurogo dan Wulandari (2011: 50-54), dismenore primer disebabkan: (1) Faktor endokring karena adanya prostaglandin F2 $\alpha$, yang merupakan stimulan miometrium poten dan vasokonstriktor pada endometrium. Kadar prostaglandin yang meningkat selalu ditemui pada wanita yang mengalami dismenore dan tentu saja berkaitan erat dengan derajat nyeri yang ditimbulkan. Peningkatan kadar ini dapat mencapai 3 kali dimulai dari fase proliferatif hingga fase luteal, dan bahkan makin bertambah ketika menstruasi. Peningkatan kadar prostaglandin inilah yang meningkatkan tonus miometrium dan kontraksi uterus yang berlebihan. Adapun hormon yang dihasilkan pituitari posterior yaitu vasopresin yang terlibat dalam penurunan aliran menstrual dan terjadinya dismenore. (2) Kelainan organik, seperti retrofleksia uterus (kelainan letak-arah anatomis rahim), hipoplasia uterus (perkembangan rahim yang tidak lengkap), obstruksi kanalis servikalis (sumbatan saluran jalan lahir), mioma submukosa bertangkai (tumor jinak yang terdiri dari jaringan otot), dan polip endometrium. (3) Faktor konsitusional, dimana faktor-faktornya seperti anemia dan penyakit menahun. (4) Faktor kejiwaan atau gangguan psikis, seperti rasa bersalah, ketakutan seksual, takut hamil dan imaturitas (belum mencapai kematangan). (5) Faktor alergi, penyebab alergi adalah toksin haid. Menurut riset, ada hubungan antara dismenore dengan artikaria (biduran), migrain, dan asma. Dan (6) Kelainan letak uterus seperti retrofleksi, hiperantefleksi, dan retrofleksi terfiksasi sehingga uterus harus bekerja ekstra untuk mengeluarkan darah sehingga hal ini dapat menimbulkan rasa nyeri.

Hasil penelitian mengemukakan bahwa pengetahuan remaja tentang faktor penyebab yang mempengaruhi dismenore sebagian besar dalam kriteria cukup yaitu sebanyak 21 responden $(55,3 \%)$. Dari hasil penelitian tersebut terdapat kesesuai antara pengetahuan remaja sebelumnya tentang gangguan menstruasi dan pengertian dysmenorhoe yang cukup. Hal ini dipengaruhi oleh kurangnya pengalaman yang di dapat oleh remaja selama memasuki akhir balik atau mulai mengalami menstruasi.

Namun, hal ini tidak sejalan dengan penelitian yang pernah dilakukan oleh Musakkar (2012:33), gambaran pengetahuan siswi kelas I tentang dismenorea di SMA Karya Sahari Bulukumba, yang mengemukakan hasil penelitian aspek penyebab dismenorea terdapat 41 responden $(48,23 \%)$ dari 85 responden yang memiliki berpengetahuan baik.

\section{3) Gejala dismenore}

Bentuk dismenore yang banyak dialami oleh remaja adalah kekakuan atau kejang di bagian bawah perut. Rasanya sangat tidak nyaman sehingga menyebabkan mudah marah, gampang tersinggung, mual, muntah, kenaikan berat badan, perut kembung, punggung terasa nyeri, sakit kepala, timbul jerawat, tegang, lesu, dan depresi. Gejala ini datang sehari sebelum haid dan berlangsung 2 hari sampai berakhirnya masa haid (Larasa 2016: 80).

Sedangkan menurut Nugroho (2014: 4), dismenore menyebabkan nyeri yang dirasakan hilang timbul dan terjadi terus-menerus yang terasa pada perut bagian bawah. Nyeri yang dirasakan akan terjadi sebelum dan selama menstruasi.

Hasil penelitian mengemukakan bahwa pengetahuan remaja tentang gejala dismenore sebagian besar dalam kriteria yang sebanding antara baik dan cukup yaitu masing-masing sebanyak 14 responden (36,8\%). Sehingga hal tersebut tidak sesuai dengan pengetahuan remaja tentang variabel sebelumnya. Hal ini menimbulkan pemahaman bahwa sebagian besar responden 
mengetahuai tentang gejala dari rasa sakit yang dialami saat menstruasi namun tidak mengetahui tentang pengertian dan faktor penyebab yang mempengaruhi sehingga rasa sakit itu terjadi.

Hal ini tidak sejalan dengan hasil penelitian yang diapatkan oleh peneliti sebelumnya oleh Defi Nafiroh dan Nuke Devi Indrawati, 2013: 157 - 166, Gambaran Pengetahuan Remaja Tentang Dismenore Pada Siswa Putri Di Mts Nu Mranggen Kabupaten Demak. Hasil penelitian yang diperoleh adalah mayoritas responden merupakan remaja pertengahan (umur 13 - 15 tahun) yaitu $84,8 \%$ dan mayoritas responden memiliki pengetahuan kurang tentang Dismenore sebesar 78,3\%. Kesimpulan mayoritas responden memiliki pengetahuan kurang tentang Dismenore yaitu sebesar 36 siswi $(78,3 \%)$.

\section{4) Pencegahan dismenore}

Pencegahan dismenore menurut Priyanti (2014: 5) dalam penelitiannya menyeburtkan adalah :

a) Menghindari stres

b) Miliki pola makan yang teratur dengan asupan gizi yang memadai, memenuhi standar 4 sehat 5 sempurna

c) Saat menjelang haid, sebisa mungkin menghindari makanan yang cenderung asam dan pedas

d) Istirahat yang cukup, menjaga kondisi agar tidak terlalu lelah, dan tidak menguras energi secara berlebihan

e) Tidur yang cukup, sesuai standar keperluan masing-masing 6-8 jam sehari

f) Lakukan olahraga ringan secara teratur

Adapun cara lain untuk menghindari atau mencegah dismenore dengan tidak tersugesti atau terpengaruh oleh perkataan maupun cerita dari orang yang pernah mengalami dismenore pada saat mentruasi.

Hasil penelitian mengemukakan bahwa pengetahuan remaja tentang pencegahan dismenore sebagian besar dalam kriteria cukup yaitu sebanyak 20 responden (52,6\%).Berdasarkan hasil penelitian yang di dapat kembali membuktikan bahwa kurangnya pengalaman dan wawasan remaja menjadi penyebab penyetahuan mereka yang terbatas, hal ini juga diperkuat dengan pendapat masyarakat sekitar yang mengaku kurang mendapat perhatian dari petugas kesehatan baik berupa penyuluhan maupun poster yang di pasang sebagai sumber informasi massa dari petugas kesehatan setempat.
Hal ini tidak sejalan dengan penelitian yang pernah dilakukan oleh Sofia Februanti, 2017: 157 - 165, Pengetahuan Remaja Putri Tentang Penanganan Dismenore Di SMP Negeri 9 Tasikmalaya. Hasil penelitian menunjukkan tingkat pengetahuan remaja putri tentang penanganan dismenore di SMPN 9 Tasikmalaya sebanyak 31 orang berpengetahuan baik (50\%), 25 orang berpengetahuan cukup $(40,3 \%)$ dan 6 orang berpengetahuan kurang $(9,7 \%)$.

\section{5) Penanganan dismenore}

Larasa (2016: 80), mengatakan untuk mengatasi nyeri haid ini dapat digunakan obat anti inflamasi non-steroid untuk mengurangi gejala yang ditimbulkan. Terapi farmakologis dasar dapat dengan pemberian obat anti inflamasi non-steroid (NSAID). Sedangkan untuk terapi nonfarmakologis terdapat beberapa cara yaitu dengan kompres air hangat, olah raga, dan tidur cukup.

Selain itu penatalaksanaan dismenore menurut hasil penelitian yang telah dilakukan sebelumnya oleh beberapa peneliti yaitu secara nonfarmakologi dimana ditemukan hasil oleh Salbiah abdominal stretching dapat menurunkan tingkat nyeri saat menstruasi ini sejalan dengan penelitian sebelumnnya oleh Marlinda (2013: 120), yang menemukan hal yang sama dimana senam dapat menurunkan tingkat nyeri menstruasi. Marlina Eli (2012: 94), dalam penelitiannya menemukan minum kunyit dapat mengurangi gejala dismenore. Ningsih (2013: 73), mendaptkan hasil paket pereda nyeri dimana ini merupakan kombinasi antara abdominal stretching exercise dan terapi minum air putih dapat digunakan sebagai alternatif untuk mengatasi dismenore. Hastuti Piju (2016: 81), menemukan alternatif lain yaitu dengan minum jus wortel terbukti dapat mengatasi dismenore. Dan Silvanus (2017: 589), menemukan regulasi emosi dapat mengatasi dismenore.

Hasil penelitian mengemukakan bahwa pengetahuan remaja tentang penanganan dismenore sebagian besar dalam kriteria cukup yaitu sebanyak 26 responden $(68,4 \%)$. Semua ini sejalan dengan informasi yang diperoleh dari orang tua para remaja dimana merekapun tidak memiliki cara maupun pengalaman dalam mengatasi rasa nyeri saat menstruasi selain dengan berbaring atau beristirahat. Hal inilah yang secara turun temurun dilakukan oleh remaja saat mengalami rasa nyeri saat menstruasi. 
Hal ini tidak sejalan dengan penelitian yang pernah dilakukan oleh Sofia Februanti, 2017: 157 - 165, Pengetahuan Remaja Putri Tentang Penanganan Dismenore Di SMP Negeri 9 Tasikmalaya. Hasil penelitian menunjukkan tingkat pengetahuan remaja putri tentang penanganan dismenore di SMPN 9 Tasikmalaya sebanyak 31 orang berpengetahuan baik $(50 \%), \quad 25$ orang berpengetahuan cukup $(40,3 \%)$ dan 6 orang berpengetahuan kurang $(9,7 \%)$.

\section{6) Dismenore}

Notoatmodjo (2012: 20), mengemukakan salah satu faktor yang memengaruhi pengetahuan adalah umur. Semakin bertambahnya umur akan berpengaruh terhadap tingkat pengetahuan yang dimiliki dan bagaimana cara mendapatkan informasi tersebut. Jika seseorang memiliki umur yang cukup maka akan memiliki pola pikir dan pengalaman yang matang pula. Umur akan sangat berpengaruh terhadap daya tangkap sehingga pengetahuan diperolehnya akan semakin baik.

Secara keseluruhan hasil penelitian mengemukakan bahwa pengetahuan remaja tentang dismenore sebagian besar dalam kriteria kurang yaitu sebanyak 30 responden $(78,9 \%)$.Dengan hasil penelitian yang di peroleh membuktikan bahwa remaja di Kelurahan Benjala memang memiliki pengetahuan yang cukup dan terbatas. Hal ini diperkuat oleh informasi yang diperoleh dari pemerintah setempat dan responden yang mengatakan bahwa tidak pernah ada peran petugas kesehatan setempat untuk memberikan penyuluhan terhadap remaja.

Hal ini sejalan dengan hasil penelitian yang diapatkan oleh peneliti sebelumnya oleh Defi Nafiroh dan Nuke Devi Indrawati, 2013: 157 - 166, Gambaran Pengetahuan Remaja Tentang Dismenore Pada Siswa Putri Di Mts Nu Mranggen Kabupaten Demak. Hasil penelitian yang diperoleh adalah mayoritas responden merupakan remaja pertengahan (umur 13 - 15 tahun) yaitu 84,8\% dan mayoritas responden memiliki pengetahuan kurang tentang Dismenore sebesar 78,3\%. Kesimpulan mayoritas responden memiliki pengetahuan kurang tentang Dismenore yaitu sebesar 36 siswi $(78,3 \%)$.

\section{KESIMPULAN}

Berdasarkan hasil penelitian dan pembahasan mengenai gambaran pengetahuan remaja putri tentang dismenore di Kelurahan Benjala Kecamatan Bontobahari Kabupaten Bulukumba jumlah sampel 38 responden dapat disimpulkan sebagai berikut:

1. Gambaran pengetahuan remaja putri tentang gangguan menstruasi di Kelurahan Benjala Kecamatan Bontobahari Kabupaten Bulukumba sebagian besar dalam kategori cukup yaitu sebanyak 25 responden $(65,8 \%)$.

2. Gambaran pengetahuan remaja putri tentang pengertian dismenore di Kelurahan Benjala Kecamatan Bontobahari Kabupaten Bulukumba sebagian besar dalam kategori cukup yaitu sebanyak 19 responden $(50,0 \%)$.

3. Gambaran pengetahuan remaja putri tentang faktor penyebab yang mempengaruhi dismenore di Kelurahan Benjala Kecamatan Bontobahari Kabupaten Bulukumba sebagian besar dalam kategori cukup yaitu sebanyak 21 responden $(55,3 \%)$.

4. Gambaran pengetahuan remaja putri tentang gejala dismenore di Kelurahan Benjala Kecamatan Bontobahari Kabupaten Bulukumba sebagian besar dalam kategori yang sebanding antara baik dan cukup yaitu masing-masing sebanyak 14 responden $(36,8 \%)$.

5. Gambaran pengetahuan remaja putri tentang pencegahan dismenore di Kelurahan Benjala Kecamatan Bontobahari Kabupaten Bulukumba sebagian besar dalam kategori cukup yaitu sebanyak 20 responden $(52,6 \%)$.

6. Gambaran pengetahuan remaja putri tentang penanganan dismenore di Kelurahan Benjala Kecamatan Bontobahari Kabupaten Bulukumba sebagian besar dalam kategori cukup yaitu sebanyak 26 responden $(68,4 \%)$.

7. Gambaran pengetahuan remaja putri tentang dismenore di Kelurahan Benjala Kecamatan Bontobahari Kabupaten Bulukumba sebagian besar dalam kategori kurang yaitu sebanyak 30 responden $(78,9 \%)$.

\section{DAFTAR PUSTAKA}

1) Ali, M, \& Asrori, M. 2015. Psikologi Remaja Perkembangan Peserta Didik. Jakarta: PT Bumi Aksara

2) Anurogo, D dan Wulandari, A. 2011. Cara Jitu Mengatasi Nyeri Haid. Jogjakarta: C.V Andi

3) Asma'ulludin, K.A. 2016.Kejadian Dismenore Berdasarkan karakteristik Orang Dan Waktu Serta Dampaknya Pada Remaja Putri SMA Dan Sederajat Di Jakarta Barat Tahun 2015. Jakarta: Universitas Islam Negeri Syarif Hidayatullah. Skripsi 
4) Budiman dan Riyanto A. 2013. Kapita Selekta Kuesioner Pengetahuan Dan Sikap Dalam Penelitian Kesehatan. Jakarta: Salemba Medika pp 66-69.

5) Februanti, S. 2017. Pengetahuan Remaja Putri Tentang Penanganan Disminore Di SMPN 9 Tasikmalaya. Jurnal Kesehatan Bakti Tunas Husada. Vol: 17, No.1, 157-165

6) Gustina, T. 2015. Hubungan Antara Usia Menarche Dan Lama Menstruasi Dengan Kejadian Dismenore Primer Pada Remaja Putri Di SMK Negeri 4 Surakarta. Surakarta: Universitas Muhammadiyah Surakarta. Skripsi

7) Hastuti, P., Sumiyati, dan Aini, N.F. 2016. Pengaruh Pemberian Air perasan Wortel Terhadap Berbagai Tingkat Nyeri Dismenore Pada Mahasiswi. Jurnal Riset Kesehatan. ISSN: 2252-5068 Vol:5, No. 2, 7982.http://ejournal.poltekkessmg.ac.id/ojs/index.php/jrk(diakses pada tanggal 8 November 2018)

8) Hidayat, A.A. 2014. Metode Penelitian Keperawatan Dan Teknis Analisis Data. Jakarta: Salemba Medika

9) Indriani, D. 2013. Keperawatan Maternanitas. Yogyakarta: Graha Ilmu.

10) Judha Mohammad, et.al. 2012. Teori Pengukuran Nyeri dan Nyeri Persalinan. Yogyakarta: Nuha Medika

11) Karnita, R. 2014. Gambaran Pengetahuan Dan Sikap Remaja Putri Tentang Personal Hygiene Organ Reproduksi Di Mts. Guppi Samata Kabupaten Gowa. Makassar: Fakultas Ilmu Kesehatan Prodi Kebidanan Universitas Islam Negeri Alauddin Makassar. Skripsi

12) Kemenkes RI.2014. INFODATIN: Status Kesehatan Reproduksi Remaja. Jakarta: Kementrian Kesehatan RI.

13) Khotimah, H., Kirnantoro, Cahyawati, E.F. 2014. Pengetahuan Remaja Putri Tentang Menstruasi Dengan Sikap Menghadapi dismenore Kelas XI Di SMA Muhammadiyah 7 Yogyakarta. Jurnal Ners Dan Kebidanan. ISSN 2354-7642 Vol: 2, No.3, 136-140

14) Kumalasari, I dan Andhyantoro, I. 2013. Kesehatan Reproduksi. Jakarta: Salemba Medika

15) Kusmiran, E. 2013. Kesehatan Reproduksi Remaja Dan Wanita. Jakarta: Salemba Medika

16) Laila, N.N, 2011. Buku Pintar Menstruasi Plus Solusi Mengatasi Segala Keluhannya. Jogjakarta: Buku Biru
17) Larasa Ta dan Alatas Faridah. 2016. Dismenore Primer Dan Faktor Risiko Dismenore Primer Pada Remaja. Majority Jurnal. Vol: 5, No.3, 79-84

18) Lestari Dewi, S.M.N. 2013. Pengaruh Dismenore Pada Remaja. Bali: Universitas Pendidikan Ganesha. Skripsi

19) Lestari, Metusala H, Suryanto J, Yulianti D. 2010. Gambaran Dismenore Pada Remaja Putri Sekolah Menengan Pertama Di Manado. Sari Pediatri. Vol: 12, No. 2, 111-125

20) Manuaba. 2010. Penanganan Dismenore(http: sehat.com(online)), diakses tanggal 29 Oktober 2018.

21) Marlinda, R., Rosalina, Purwaningsih, P. 2013. Pengaruh Senam Dismenore Terhadap Penurunan Dismenore Pada Remaja Putri Di Desa Sidoharjo Kecamatan Pati. Jurnal Keperawatan Maternitas. Vol: 1, No.2, 118123

22) Marlina Eli. 2012. Pengaruh Minum Kunyit Terhadap Nyeri Dismenore Primer Pada Remaja Putri Di SMA Negeri 1 Tanjung Mutiara Kabupaten Agem. Universitas Andalas. KTI

23) Mulasti. 2013. Hubungan Status Gizi Dengan kejadian Dismenore Remaja Putri Di SMA Islam Al-Hikmah Jepara. Jepara: Akbid Islam Al-Hikmah. KTI

24) Musakkar, Fatmawati. 2012. Gambaran Pengetahuan Siswi Kelas I Tentang Dismenorea Di SMA Karya Sahari Bulukumba. Bulukumba. Akademi Kebidanan Tahirah Al Baeti Bulukumba. KTI

25) Nafiroh, D. dan Indrawati, D.N. 2013. Gambaran Pengetahuan Remaja Tentang Dismenore Pada Siswi Putri Di Mts Nu Mranggen Kabupaten Demak. Jurnal Ilmiah Kebidanan. Vol: 4, No.1, 157-166

26) Nugroho, et.al. 2014. Masalah Kesehatan Remaja. Jakarta: Salemba Medika

27) Niken Purborini. 2017. Gambaran Tingkat Pengetahuan Remaja Putri Kelas VII Tentang Perubahan Fisik Pada Masa Pubertas Di SMP Muhammadyah 1 Sendangadimlati, Sleman, Yogyakarta. Yogyakarta: Sekolah Tinggi Ilmu Kesehatan Jenderal Ahmad Yani. KTI

28) http://www.permataindonesia.ac.id/wpcontent/uploads/2016/08/01-Jurnal-PI_HaniKusminatun-Dwi.pdf. (diakses 30 Oktober 2018)

29) Ningsih Ratna, Setyowati, Rahmah Hayuni. 2013. Evektivitas Paket Pereda Nyeri Pada Remaja Dengan Dismenore. Jurnal 
Keperawatan Inonesia. pISSN 1410-4490, eISSN 2354-9203 Vol: 16, No.2, 67-76

30) Notoadmodjo, S. 2012. Metodologi Penelitian Kesehatan. Jakarta: PT. Rineka Cipta

31) Novia Ika \& Puspitasari Nunik. 2018. Faktor Risiko Yang Mempengaruhi Kejadian Dismenore Primer. Sidoarjo: Universitas Airlangga. Skripsi

32) Nursalam. 2013. Metodologi Penelitian: Pendekatan Praktis (edisi 3). Jakatra: Salemba Medika

33) Pieter dan Janiwarti. 2013. Pendidikan Psikologi Untuk Bidan. Yogyakarta: Rapha Publishing.

34) Priyanti, S., Mustikasari, D.A. 2014. Hubungan Tingkat Stres Terhadap Dismenore Pada Remaja Di Madrasah Aliyah Mamba'ul Ulum Awang-awang Mojosari Mojokerto. Hospital Majapahit. Vol: 6, No. 2, 1-10

35) Rahayu Asri, pertiwi Sinar, Patimah Siti. 2017. Pengaruh Endorphine Massage Terhadap Rasa Sakit Dismenore Pada Mahasiswi Jurusan Kebidanan Poltekkes Kemenkes Tasikmalaya Tahun 2017. Jurnal Bidan. pISSN 2477-3441, eISSN 2477-345X Vol: 3, No.2, 22-30

36) Rustam Erlina. 2014. Gambaran Pengetahuan Remaja Putri Terhadap Nyeri Haid (dismenore) Dan Cara Penanggulangannya. Jurnal Kesehatan Andalas. Vol: 3 ,No., 286290

37) Sarwono. 2010 . Ilmu Kebidanan. Grafindo Persada. Jakarta

38) Sastroasmoro, S. Sofyan I. Dasar-Dasar Metodologi Penelitian Klinis Edisi Ke-5. Jakarta: CV. Sagung Seto. 2014 p:130-7,35217

39) Sasaki, K.J. 2014. Menstruasi Disorders. Medscape Drug, Diseases and Procedures. Diakses pada tanggal 07 Desember 2018

40) http://emedicine.medscape.com/article/953 945-overview.

41) Silvanus, et.al. 2017. Hubungan Regulasi Emosi Dengan Intensitas Nyeri Dismenore Primer Pada Remaja Putri Di SMAN 7 Malang. Nursing News. Vol: 2, No.3, 588-600

42) Sinaga, et.al. 2017. Manajemen Kesehatan Menstruasi. Jakarta:Universitas Nasional, IWWASH Dan Global One

43) Soekanto. 2015. Defenisi Pengetahuan. http://www.defenisidanpengetahuan.com

44) Sugiyono. 2013. Metode Penelitian Pendidikan Pendekatan Kuantitatif, Kualitatif, Dan R\&D. Bandung: Alfabeta
45) Sugiyono. 2012. Metode Penelitian Kuantitatif, Kualitatif Dan R\&D. Bandung: Alfabeta

46) Sukarni, I., dan Wahyu, P. 2013. Buku Ajar: Keperawatan Katernitas. Yogyakarta: Nuha Medika

47) Susanto N, Nasrudin dan Abdullah N. 2008. Analisa Kasus Dismenore Pada Remaja Putri Di Kotamadya Makassar. Diakses pada tanggal 23 November 2018. Skripsi http://med.unhas.ac.id/obgin/index.php/option =com_content\&task=view\&id=141\&Itemid= 63.

48) Utami,A.N.R., Jumriani Ansar dan Dian Sidik. 2013. Faktor Yang Berhubungan Dengan Kejadian Dismenore Paa Remaja Putri Di SMAN 1 Kahu Kabupaten Bone. Makassar: Univesitas Hasanuddin. Skripsi

49) Wilandania, Eliska. 2015. Gambaran Tingkat Pengetahuan Remaja Putri Tentang Gangguan Menstruasi Pada Siswi Kelas XI Di SMAN 13 Surabaya. Surabaya. University Of Nahdlatul Ulama Surabaya. KTI

50) Zegeye, D.T., Megabiaw B, Mulu A. 2009. Age At Menarche And The Menstrual Pattern Of Secondary School Adolescents In Northwest Ethppia. BMCWomen's Heal. Vol: 9, No. 29, 82-100 